\title{
Effect of $\alpha$-Tocopherol Deficiency on Carp-VI Deficiency Symptoms and Changes of Fatty Acid and Triglyceride Distributions in Adult Carp
}

\author{
Takeshi Watanabe* and Fumio Takashima* \\ (Received January 6, 1977)
}

\begin{abstract}
Adult carp weighing about $100 \mathrm{~g}$ were kept on an $\alpha$-tocopherol deficient diet for 17 months in order to examine the influence of $\alpha$-tocopherol deficiency on different tissues with special emphasis on the reproductive organs and on fatty acid and triglyceride distributions. The pattern of fatty acid changes due to the tocopherol deficiency was found to be very similar to that seen in essential fatty acid deficiency in both fish and mammals. The most marked change in fatty acid composition was the decrease of $18: 2 \omega 6$ level in both triglyceride and polar lipid fractions in most of the deficient tissues. In the deficient ovaries there were

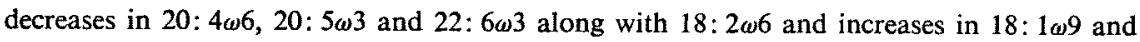
20:3 39 . The general pattern of changes in triglyceride distribution was the increase in the deficient carp of the low molecular weight triglycerides and decrease of the usually dominant C-52 to C-56 triglycerides.

The tocopherol deficiency in adult carp also revealed basically the same histological changes as those recognized in carp fingerlings. The depletion of tocopherol from the diet exerted significant effects on the pituitary-ovarian system and this clearly indicated that $\alpha$-tocopherol plays an important role in reproductive physiology in carp on the same basis as in higher animals.
\end{abstract}

In the first study of this series ${ }^{1)}$, we examined the requirments of carp for vitamin $\mathrm{E}$ and demonstrated that among its deficiency symptoms was an apparent muscular dystrophy in the fish receiving a tocopherol deficient diet. We also reported in the preceding paper $^{2)}$ that the influence of $\alpha$-tocopherol deficiency on the composition of fatty acids and triglycerides was essentially the same in both fingerlings and young carp. Following the previous experiments with fingerlings and young carp, an additional study was conducted using adult carp which had been kept on an $\alpha$-tocopherol deficient diet for the relatively long term of 17 months. This permitted an examination of the influence of $\alpha$-tocopherol deficiency on different tissues with special emphasis on reproductive organs. It was also necessary ${ }^{21}$ to see whether the type of changes in fatty acid and triglyceride distributions induced by a lack of $\alpha$-tocopherol depended on the duration of the $\alpha$-tocopherol shortage or on the size of the fish.

\section{Materials and Methods}

The experimental diet, preparation of diet, fish care and feeding were all the same as described in the previous papers ${ }^{1,2}$. Carp ranging from 76.5 to $115.5 \mathrm{~g}$ in body weight

\footnotetext{
* Tokyo University of Fisheries, Konan 4, Minato-ku, Tokyo (液辺 武・隆島史夫：東京水産大学).
} 
were distributed into 2 groups of 4 fish each and were kept for 17 months respectively on a control diet enriched with $70 \mathrm{mg}$ per $100 \mathrm{~g}$ diet of DL- $\alpha$-tocopheryl acetate or on an $\alpha$-tocopherol deficient diet.

At the end of feeding trial, carp were taken from the both groups for analyses of proximate composition, fatty acids, triglycerides, and for histological examination. All the carp from the control group and three from the experimental group were found to be female, and three female carp from each group were used for examination. The one male carp from the deficient group was used only for analysis of plasma fatty acids.

Lipids were extracted from plasma, erythrocytes, ovary, muscle, kidney and hepatopancreas by the method of NeLSON ${ }^{3 /}$ for blood and by the method of FolCH et al. ${ }^{43}$ for other tissues. For the determination of ovary fatty acids and triglycerides, lipids were extracted from each carp (designation for controls: C-1, C-2, C-3; for experimentals: E-1, E-2, E-3) and were analysed individually. All other tissues from the three carp of each dietary group were combined for analysis. The analytical procedures such as separation of polar and nonpolar lipids with a gel column, isolation of triglycerides from nonpolar lipids by TLC, preparation of methyl esters and GLC operating conditions were all the same as reported in the previous papers. ${ }^{(, 6)}$

For histological examination, paraffin sections of the epaxial muscle, Langerhans' islets, pituitary gland, thyroid gland, interrenal tissue, liver, kidney and ovary from the control and the $\alpha$-tocopherol deficient females were prepared after fixation in Bouin's fluid. These sections were stained by hematoxylin eosin(HE), Heidenhein's azocarmineorange G-aniline blue (AZAN), periodic acid-Schiff's reagent (PAS) or Gomori-Halmi's paraldehyde fuchsin (AF).

\section{Results and Discussion}

Results of the feeding experiment The growth data and the weights of ovaries are shown in Table 1. The fish receiving the diet deficient in $\alpha$-tocopherol gained signifi-

Table 1. Results of 17 months of the feeding experiment

\begin{tabular}{|c|c|c|c|c|c|}
\hline \multirow{2}{*}{ Sample } & \multicolumn{2}{|c|}{ Body weight (g) } & \multirow{2}{*}{$\begin{array}{l}\text { Percent } \\
\text { gain }\end{array}$} & \multirow{2}{*}{$\begin{array}{l}\text { Weight of } \\
\text { ovary (g) }\end{array}$} & \multirow{2}{*}{$\begin{array}{l}\text { Gonado- } \\
\text { somatic } \\
\text { index }\end{array}$} \\
\hline & Initial & Final & & & \\
\hline \multicolumn{6}{|l|}{ Control } \\
\hline C-1 & 104.5 & 505.0 & 383 & 48.7 & 9.6 \\
\hline $\mathrm{C}-2$ & 115.5 & 542.6 & 370 & 68.5 & 12.6 \\
\hline C-3 & 76.5 & 433.8 & 467 & 87.1 & 20.1 \\
\hline \multicolumn{6}{|c|}{ Experimental } \\
\hline E-1 & 108.5 & 305.7 & 182 & 6.0 & 2.0 \\
\hline E-2 & 83.5 & 150.0 & 80 & 11.0 & 7.3 \\
\hline E-3 & 98.5 & 303.2 & 208 & 2.0 & 0.7 \\
\hline
\end{tabular}


cantly less than those receiving the diet enriched with $\alpha$-tocopherol. Apparent muscular dystrophy characterized by a marked loss of flesh from the back appeared in 7 months in the deficient group and three carp of the group exhibited definite symptoms at the end of the experiment. The weight of gonad and gonad-somatic index were also significantly low in the tocopherol deficient group, suggesting that reproductive disorders were induced by a lack of $\alpha$-tocopherol, in agreement with the results of the histological examination.

Proximate and lipid compositions of the experimental fish The analytical data on the various tissues of fish at the termination of feeding trial are given in Table 2 . The results obtained for the muscle are very similar to those reported previously ${ }^{1,2,7)}$, indicating the high water content and a lowered protein content in the deficient muscle associated with the tocopherol deficiency. No significant difference in the hepatopancreas due to the absence of $\alpha$-tocopherol was observed.

Table 2. Effect of $\alpha$-tochopherol deficiency on proximate and lipid compositions of adult $\operatorname{carp}(\%)$

\begin{tabular}{|c|c|c|c|c|c|c|c|c|}
\hline \multirow{2}{*}{ Sample } & & \multirow{2}{*}{ Moisture } & \multirow{2}{*}{ Protein } & \multirow{2}{*}{ Lipid } & \multicolumn{2}{|c|}{$\%$ in Tissue } & \multicolumn{2}{|c|}{$\%$ in Tissue lipid } \\
\hline & & & & & Polar & Nonpolar & Polar & Nonpolar \\
\hline \multirow[t]{2}{*}{ Muscle } & Cont. & 79.5 & 18.9 & 0.8 & 0.6 & 0.2 & 79.0 & 21.0 \\
\hline & Exp. & 85.3 & 13.5 & 1.0 & 0.7 & 0.3 & 71.9 & 28.1 \\
\hline \multirow[t]{2}{*}{ Hepatopancreas } & Cont. & 74.5 & 18.8 & 6.4 & 3.0 & 3.4 & 46.2 & 53.8 \\
\hline & Exp. & 75.3 & 17.4 & 5.6 & 2.3 & 3.3 & 40.1 & 59.9 \\
\hline \multirow[t]{2}{*}{ Kidney } & Cont. & - & - & 4.4 & 2.5 & 1.9 & 55.6 & 44.4 \\
\hline & Exp. & - & - & 7.1 & 3.3 & 3.8 & 46.2 & 53.8 \\
\hline \multirow[t]{6}{*}{ Ovary } & C-1 & 64.5 & 27.4 & 8.0 & 5.4 & 2.6 & 67.8 & 32.2 \\
\hline & $\mathrm{C}-2$ & 63.8 & 27.8 & 8.9 & 6.6 & 2.3 & 74.3 & 25.7 \\
\hline & $\mathrm{C}-3$ & 66.0 & 26.3 & 6.8 & 4.8 & 2.0 & 71.2 & 28.8 \\
\hline & E-1 & 76.0 & 18.9 & 4.1 & 2.9 & 1.2 & 71.3 & 28.7 \\
\hline & E-2 & 82.1 & 12.3 & 5.0 & 1.6 & 3.4 & 31.2 & 68.8 \\
\hline & E-3 & 82.6 & 13.9 & 2.4 & 1.0 & 1.4 & 43.3 & 56.6 \\
\hline \multirow[t]{2}{*}{ Plasma*1 } & Cont. & - & - & 1.1 & 0.8 & 0.3 & 70.7 & 29.3 \\
\hline & Exp. & - & 一 & 1.1 & 0.6 & 0.5 & 55.8 & 44.2 \\
\hline \multirow[t]{2}{*}{ Erythrocyte*2 } & Cont. & - & - & 792 & - & - & - & - \\
\hline & Exp. & - & - & 812 & - & - & - & - \\
\hline
\end{tabular}

$* 1: \mathrm{g} / \mathrm{d} l \quad * 2: \mathrm{mg} / \mathrm{d} l$.

The ovaries from carp of the $\alpha$-tocopherol deficient group exhibited more marked changes in proximate composition than the corresponding muscle. In the ovaries moisture levels ranged from $63-66 \%$ in the control group, compared to $76-82 \%$ in the deficient group. These considerably high levels of moisture were reflected in significantly low levels of both protein and lipid. Protein and lipid levels in two of the three deficient carp decreased to about half of those in the control group. The proportion of polar lipids was also reduced in the deficient ovaries. As shown in Table 2, the average percentage of polar lipids in the tissue was $5.6 \%$ in the control group and $1.8 \%$ in the deficient group. 
This reduced level of polar lipid in the deficient ovaries may be closely related with the retardation of oocyte development as described later. On the other hand, there was no significant difference in the lipid contents of erythrocyte and plasma, although the proportion of nonpolar lipids in plasma was elevated in the $\alpha$-tocopherol depleted carp.

Fatty acid composition Tables 3 to 5 list the percentages of the major fatty acids in both the triglyceride and polar lipid fractions isolated from the various tissues of carp given respectively a diet deficient in $\alpha$-tocopherol or the same diet supplemented with the vitamin. The general pattern of changes in fatty acid distribution due to the tocopherol deficiency was found to be basically the same in every tissue examined. In most of the tissues of the deficient carp the percentage of $16: 1$ and 18:1, along with $20: 3 \omega 9$ abnormal

Table 3. Percentages of the major fatty acids of the plasma triglyceride and polar fractions of lipids from the control and the tocopherol deficient adult carp (area \%)

\begin{tabular}{|c|c|c|c|c|c|c|}
\hline \multirow{2}{*}{$\begin{array}{l}\text { Fatty } \\
\text { acid }\end{array}$} & \multicolumn{3}{|c|}{ Triglyceride $* 2$} & \multicolumn{3}{|c|}{ Polar lipid ${ }^{* 2}$} \\
\hline & 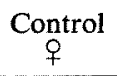 & \multicolumn{2}{|c|}{ Experimental } & $\underset{q}{\text { Control }}$ & \multicolumn{2}{|c|}{ Experimental } \\
\hline $14: 0$ & 2.3 & 3.6 & 3.8 & 1.1 & 2.5 & 2.2 \\
\hline $16: 0$ & 19.5 & 15.8 & 20.4 & 32.5 & 31.4 & 28.9 \\
\hline $16: 1 \omega 7^{* 1}$ & 11.1 & 14.6 & 17.7 & 7.0 & 9.9 & 13.0 \\
\hline $18: 0$ & 3.3 & 3.5 & 2.0 & 7.4 & 6.1 & 4.7 \\
\hline 18: $1 \omega 9^{* 1}$ & 30.0 & 42.8 & 36.6 & 22.9 & 29.3 & 23.8 \\
\hline $18: 2 \omega 6$ & 13.5 & 0.2 & 0.5 & 7.0 & 1.5 & 3.4 \\
\hline $20: 3 \omega 9$ & 0.5 & 2.0 & 3.4 & 1.2 & 5.3 & 3.6 \\
\hline $20: 4 \omega 6$ & 0.8 & - & 0.4 & 3.1 & 1.4 & 1.3 \\
\hline $20: 5 \omega 3$ & 2.4 & - & - & 1.6 & - & 0.8 \\
\hline $22: 6 \omega 3$ & 3.1 & - & 1.1 & 9.6 & 2.3 & 5.0 \\
\hline
\end{tabular}

*1 Small amounts of the other monoenes were included in the figures.

*2 The average value of 3 samples for female, and the value from the one male deficient carp was presented only for a limited comparison.

Table 4. Percentages of the major fatty acids of the triglyceride and polar fractions of lipids from the ovaries of the control and the tocopherol deficient adult carp (area \%)

\begin{tabular}{|c|c|c|c|c|c|c|c|c|c|c|c|c|}
\hline \multirow{2}{*}{$\begin{array}{l}\text { Fatty } \\
\text { acid }\end{array}$} & \multicolumn{6}{|c|}{ Triglyceride } & \multicolumn{6}{|c|}{ Polar lipid } \\
\hline & $\mathrm{C}-1$ & $\mathrm{C}-2$ & C-3 & E-1 & E-2 & E-3 & $\mathrm{C}-1$ & $\mathrm{C}-2$ & $\mathrm{C}-3$ & E-1 & $\mathrm{E}-2$ & E-3 \\
\hline $14: 0$ & 2.6 & 2.3 & 2.2 & 5.2 & 4.8 & 5.9 & 1.2 & 0.8 & 1.0 & 1.2 & 1.6 & 2.1 \\
\hline 16:0 & 20.0 & 22.5 & 23.3 & 14.4 & 15.1 & 16.6 & 26.8 & 28.1 & 24.4 & 20.2 & 22.5 & 24.2 \\
\hline $16: 1 \omega 7^{*}$ & 13.9 & 15.4 & 11.5 & 14.4 & 16.1 & 16.6 & 4.5 & 4.5 & 4.9 & 7.8 & 10.5 & 7.3 \\
\hline 18: 0 & 2.3 & 2.8 & 2.5 & 1.9 & 4.9 & 2.8 & 5.0 & 6.2 & 6.3 & 7.6 & 6.3 & 4.5 \\
\hline $18: 1 \omega 9^{*}$ & 36.7 & 37.2 & 42.5 & 51.8 & 46.7 & 45.3 & 16.3 & 17.2 & 17.8 & 20.2 & 24.9 & 14.8 \\
\hline $18: 2 \omega 6$ & 13.9 & 11.1 & 7.9 & 1.5 & 1.2 & 1.4 & 5.3 & 6.4 & 5.6 & 1.3 & 0.4 & 1.2 \\
\hline $20: 3 \omega 9$ & - & - & - & - & - & - & 0.1 & 0.3 & 0.3 & 6.9 & 9.6 & 3.4 \\
\hline $20: 3 \omega 6$ & 1.2 & 1.3 & 1.4 & 0.6 & - & - & 1.2 & 1.5 & 1.2 & 0.7 & 0.6 & 0.2 \\
\hline $20: 4 \omega 6$ & 1.0 & 1.1 & 0.7 & - & - & - & 4.4 & 4.6 & 5.9 & 3.9 & 2.1 & 3.2 \\
\hline $20: 5 \omega 3$ & 0.7 & 0.1 & 0.2 & - & - & - & 3.4 & 2.9 & 3.1 & 1.6 & 0.6 & 2.7 \\
\hline $22: 6 \omega 3$ & 1.7 & 1.3 & 1.7 & 0.3 & tr & 0.6 & 23.1 & 20.6 & 21.1 & 12.1 & 11.3 & 5.3 \\
\hline
\end{tabular}

* Small amounts of the other monoenes were included in the figures. 
Table 5. Percentages of the major fatty acids of the triglyceride and polar lipid fractions from the muscle, hepatopancreas and kidney of the control and the tocopherol deficient adult carp (area \%)

\begin{tabular}{|c|c|c|c|c|c|c|c|c|c|c|c|c|}
\hline \multirow{3}{*}{$\begin{array}{l}\text { Fatty } \\
\text { acid }\end{array}$} & \multicolumn{6}{|c|}{ Triglyceride } & \multicolumn{6}{|c|}{ Polar lipid } \\
\hline & \multicolumn{2}{|c|}{ Muscle } & \multicolumn{2}{|c|}{$\begin{array}{l}\text { Hepato- } \\
\text { pancreas }\end{array}$} & \multicolumn{2}{|c|}{ Kidney } & \multicolumn{2}{|c|}{ Muscle } & \multicolumn{2}{|c|}{$\begin{array}{l}\text { Hepato- } \\
\text { pancreas }\end{array}$} & \multicolumn{2}{|c|}{ Kidney } \\
\hline & Cont & Exp & Cont & Exp & Cont & Exp & Cont & Exp & Cont & Exp & Cont & Exp \\
\hline $14: 0$ & 2.2 & 3.6 & 1.9 & 3.6 & 2.6 & $5.4^{\circ}$ & 1.0 & 1.5 & 1.1 & 1.5 & 1.1 & 4.1 \\
\hline $16: 0$ & 20.5 & 19.0 & 16.5 & 15.9 & 18.6 & 16.6 & 14.0 & 19.4 & 22.4 & 20.5 & 24.3 & 25.3 \\
\hline $16: 1 \omega 7^{*}$ & 8.1 & 13.8 & 9.3 & 12.8 & 9.3 & 17.3 & 4.5 & 7.8 & 5.4 & 8.7 & 4.9 & 8.4 \\
\hline 18:0 & 3.7 & 3.0 & 3.7 & 5.3 & 4.8 & 2.8 & 4.6 & 6.4 & 7.1 & 6.2 & 10.5 & 4.4 \\
\hline $18: 1 \omega 9^{*}$ & 29.8 & 44.6 & 39.9 & 50.9 & 30.9 & 48.8 & 24.0 & 24.7 & 13.3 & 19.9 & 17.0 & 22.2 \\
\hline $18: 2 \omega 6$ & 14.8 & 1.3 & 8.2 & 0.5 & 17.3 & 1.7 & 7.2 & 1.6 & 4.8 & 1.0 & 6.4 & 1.0 \\
\hline $20: 1 \omega 9^{*}$ & 6.5 & 4.1 & 4.9 & 3.5 & 6.5 & 3.4 & 2.2 & 1.3 & 1.1 & 1.8 & 1.4 & 6.3 \\
\hline $20: 3 \omega 9$ & - & - & - & - & - & - & 0.7 & 7.4 & 1.0 & 9.7 & 0.8 & 8.6 \\
\hline $20: 3 \omega 6$ & - & - & - & - & - & - & 0.8 & 0.6 & 1.4 & 0.8 & 1.5 & - \\
\hline $20: 4 \omega 6$ & - & - & - & - & - & - & 3.1 & 2.6 & 8.7 & 3.7 & 9.1 & 6.2 \\
\hline $20: 5 \omega 3$ & 3.7 & 0.5 & 3.8 & $\operatorname{tr}$ & 2.6 & 0.3 & 6.6 & 1.8 & 2.3 & 0.5 & 5.6 & - \\
\hline $22: 6 \omega 3$ & 4.6 & 1.3 & 6.9 & - & 1.3 & - & 24.7 & 15.7 & 26.9 & 20.3 & 9.8 & 1.7 \\
\hline
\end{tabular}

* Small amounts of the other monoenes were incluedd in the figures.

eicosatriene, increased, whereas the percentage of both $\omega 6$ fatty acids such as $18: 2 \omega 6$ and

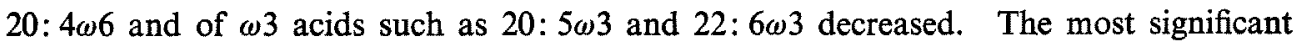
change observed was the marked decrease of 18: $2 \omega 6$ level in all the tissues, especially in the triglyceride fraction of plasma, ovary and muscle. In these tissues the percentage of $18: 2 \omega 6$ was approximately $14 \%$ in all fish of the control group, but respectively $0.2,1.4$ and $1.3 \%$ in the deficient group. The increase of $18: 1 \omega 9$ was also significant in these tissues of the deficient group. These results are in good agreement with those observed in the previous experiments conducted using fingerlings ${ }^{8}$ and young carp ${ }^{2}$. The increases of $20: 3 \omega 9$ and the decrease of other polyunsaturated fatty acids were more marked in the polar lipid fractions than in the triglyceride fractions. This type of changes in the concentration of polyunsaturated fatty acids was not observed in the previous relatively short term feeding study with carp fingerlings.

Table 3 lists the percentages of the major fatty acids of plasma lipids from male and female carp. The influence of $\alpha$-tocopherol deficiency on fatty acid composition seemed to differ according to the sex of the fish and as shown in Table 3 appeared to be somewhat milder for male carp than for females.

Triglyceride composition The triglyceride compositions of ovary, muscle, hepatopancreas and kidney are summarized in Table 6. Each lipid showed triglyceride distribution from C-38 to C-58 and the dominant components were C-50 to C-54 triglycerides as observed previously ${ }^{2,8}$. In the ovary of the deficient fish the decrease of C-50 and C-52 triglycerides was reflected in a marked increase in the levels of C-38 to C-48, and 
Table 6. Effect of $\alpha$-tocopherol deficiency on the triglyceride distribution in the muscle, hepatopancreas, kidney and ovary of the control and the tocopherol deficient adult carp (area \%)

\begin{tabular}{|c|c|c|c|c|c|c|c|c|c|c|c|c|}
\hline \multirow{2}{*}{ Triglyceride* } & \multicolumn{2}{|c|}{ Muscle } & \multicolumn{2}{|c|}{$\begin{array}{l}\text { Hepato- } \\
\text { pancreas }\end{array}$} & \multicolumn{2}{|c|}{ Kidney } & \multicolumn{6}{|c|}{ Ovary } \\
\hline & Cont & Exp & Cont & Exp & Cont & Exp & C-1 & C-2 & $\mathrm{C}-3$ & E-1 & E-2 & E-3 \\
\hline C-38 & - & 0.3 & - & - & - & 3.0 & - & - & - & 0.2 & 0.5 & 0.5 \\
\hline C- -40 & - & 0.6 & - & 0.5 & - & 3.9 & - & 0.1 & - & 1.0 & 2.0 & 1.6 \\
\hline C-42 & tr & 1.4 & $\operatorname{tr}$ & 1.5 & tr & 6.0 & tr & 0.2 & $\operatorname{tr}$ & 3.6 & 4.5 & 4.8 \\
\hline C-44 & 0.6 & 2.1 & 0.9 & 2.2 & 0.3 & 6.7 & $\operatorname{tr}$ & 1.3 & 0.8 & 3.7 & 6.0 & 5.6 \\
\hline C-46 & 4.2 & 5.2 & 1.9 & 5.0 & 0.9 & 10.8 & 4.9 & 2.7 & 5.1 & 10.0 & 13.0 & 11.0 \\
\hline C-48 & 7.4 & 10.9 & 7.4 & 10.5 & 3.6 & 14.4 & 9.8 & 10.9 & 8.4 & 17.6 & 17.1 & 16.3 \\
\hline C-50 & 20.6 & 22.7 & 22.1 & 21.9 & 27.1 & 18.0 & 26.2 & 30.0 & 30.0 & 21.0 & 21.7 & 21.8 \\
\hline C-52 & 32.4 & 31.2 & 35.8 & 33.4 & 31.4 & 19.7 & 34.3 & 35.2 & 38.9 & 25.1 & 23.3 & 23.7 \\
\hline C-54 & 24.0 & 19.6 & 25.0 & 21.6 & 24.2 & 12.0 & 19.0 & 15.7 & 15.7 & 15.7 & 10.1 & 11.7 \\
\hline C-56 & 10.6 & 5.8 & 7.0 & 3.4 & 9.4 & 2.4 & 5.9 & 4.0 & 1.1 & 2.1 & 1.2 & 2.7 \\
\hline C-58 & 0.2 & - & - & - & 3.0 & - & $\operatorname{tr}$ & $\operatorname{tr}$ & $\operatorname{tr}$ & tr & $\operatorname{tr}$ & tr \\
\hline
\end{tabular}

* Trace amounts of C-odd triglycerides were detected and were not calculated.

especially of C-46 and C-48 triglycerides. In the muscle and hepatopancreas the percentages of C-54 and C-56 triglycerides decreased in the deficient carp. The kidney of the experimental group exhibited the most marked changes in triglyceride composition. In the kidney the triglycerides from C-50 to C-56 all decreased, and correspondingly the low molecular triglycerides from C-38 to C-48 increased. Thus, the general pattern of changes in triglyceride distribution in this experiment with adult carp was the increase in the deficient carp of the low molecular weight triglycerides and decrease of the usually dominant C-52 to C-56 triglycerides.

Histological changes The effects of $\alpha$-tocopherol deficiency on adult carp were found to be essentially the same as those observed in carp fingerlings ${ }^{11}$.

In the epaxial muscle of the deficient carp many of the fibers were degenerative. Some were completely atrophic and the others displayed hyaline or granular degeneration.

As shown in Fig. 2, AF positive cells in the Langerhans' islets, which are believed to secrete insulin, were fewer in number and smaller in size in the deficient fish. Secretory granules were also fewer.

The urinary tubules of the deficient fish were hypertrophic and their lumina were enlarged. Contrary to the findings with fingerlings ${ }^{11}$, degenerative changes such as thickening of the basement membrane, disappearance of urinary tubules, and necrosis of the glomeruli were not as common. The only noticeable change observed in the deficient fish was glycogen infiltration in the epithelial cells of urinary tubules.

In the deficient fish, the liver cells were small and contained less glycogen. Most of the nuclei seemed to be normal, but some were pycnotic (Fig. 4).

In the pituitary gland of the deficient fish, AF positive cells of mesoadenohypophysis 
were fewer in number, and showed less affinity for AF (Fig. 6). AF positive cells in the mesoadenohypophysis of the teleost are thought to be either gonadotrophs or the thytotrophs ${ }^{9)}$. Under $\alpha$-tocopherol deficient conditions they were fewer in number and stained very weakly, as mentioned above and in the previous paper. These figures seem to indicate lowered secretory activity of both the gonadotrophs and thyrotrophs. In fact, in the deficient fish thyroid epithelial height was found to be low and the accumulation of yolkgranules in the oocytes was insufficient as described below. $\alpha$-Tocopherol plays a role essential for maintaining normal function of certain endocrine organs in higher animals and its deficiency evokes hypofunctional changes in anterior pituitary basophils and eosinophils of rats ${ }^{10,11}$. The adrenocortical layers and thyroid glands of the deficient animals also show hypofunctional states. ${ }^{11,12)}$ Probably the degenerative changes of pituitary basophils induced by the $\alpha$-tocopherol deficiency resulted in hypofunctional states in the gonad, thyroid gland and adenocortical layer. In the previous paper $^{1 /}$, we reported that $\alpha$-tocopherol deficiency resulted in hypofunctional changes in AF positive cells of the mesoadenohypophysis in carp fingerlings. In this experiment with adult carp the tocopherol deficiency evoked again hypofunctional changes in the cells. These results seem to indicate that $\alpha$-tocopherol is essential not only for mammals but also for carp in order to maintain normal function of the pituitary gland.

As shown in Table 1, ovaries of the deficient fish were smaller than those of the control fish. The gonado-somatic index (the percentage of ovary weight to body weight) was 3.3 in the experimental group and 14.1 in the control group. The most remarkable differences observed between the groups are illustrated in Figs. 7 and 8 . In the deficient ovaries there were no oocytes which accumulated plentiful yolk-granules and yolkvesicles, although small amounts of atretic oocytes could also be found in the control ovaries. Moreover, these atretic oocytes were relatively small and did not exceed $500 \mu$ in diameter. This indicates that the oocytes which accumulated the yolk-granules to some extent fell into an atretic condition during relatively younger stages. Carp oocytes usually begin to form light microscopically visible yolk-vesicles when they have attained $150-200 \mu$ in diameter. However, the oocytes in the deficient fish seldom deposited the vesicles even though they have developed to that size. $\alpha$-Tocopherol was first shown to be involved in prevention of sterility and fetal resorption in rats ${ }^{13,14)}$. For example, $\mathrm{Ko}^{15}$ ) examined the vitamin $\mathrm{E}$ deficiency in rats and found the disappearance of mature ovarian follicles. These findings indicate that $\alpha$-tocopherol is deeply concerned in the normal function of reproductive organs. In the previous study ${ }^{11}$, we could not recognize these changes in reproductive organs because of the immaturity of the fingerlings. However in this experiment with adult carp it was confirmed that the $\alpha$-tocopherol deficiency brought about the retardation of oocytes development, or essentially the same effect as that observed in mammals. This result indicates that $\alpha$-tocopherol is also indispensable for suc- 
cessive development of the oocytes in carp.

On the other hand, there was no appreciable change in interrenal tissues. The cellular size and nuclear size of interrenal cells and of chromaffin cells were not different between the two groups.

The results obtained in this study show that the influence of $\alpha$-tocopherol deficiency on fatty acid composition of carp tissues is essentially the same regardless of the fish size and that the type of changes in fatty acid distribution due to the tocopherol deficiency depends upon the length of time the carp are given a diet deficient in $\alpha$-tocopherol. The influence seems to be more marked in long term deprivation. The most marked change

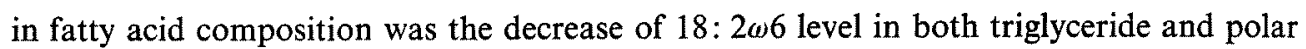
lipid fractions in most of the tissues.

The changes found in the fatty acid content of the ovary are perhaps the most interesting and most important, since the principal sign of $\alpha$-tocopherol deficiency in the adult female carp is ovary degeneration. In the deficient ovaries there were decreases in 20:

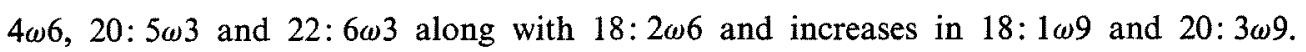
The same results have been reported by LEE and BARNES ${ }^{16)}$ and SUzUKI ${ }^{17)}$ in the case of rat testes. This pattern of fatty acid changes is very similar to that seen in essential fatty acid (EFA) deficiency in both fish ${ }^{18-20)}$ and mammals. ${ }^{21}$ It is possible to postulate that the depletion of $\alpha$-tocopherol from the diet resulted in a low level of 18:2 26 which is one of the EFA for carp ${ }^{20}$ and that the reduced level of 18: $2 \omega 6$ may have caused a secondary EFA deficiency in the $\omega 3$ family of fatty acids.

In the plasma triglyceride fraction a marked decrease of $18: 2 \omega 6$ was reflected in an

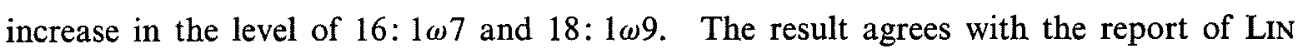
and HoRNING ${ }^{22)}$ that the major change in structure for human plasma lipids in the $\alpha$ tocopherol depleted state is replacement of linoleic acid by oleic acid. Analytical data of UNDERWOOD et al. ${ }^{23)}$ also show a significant decrease in linoleic acid for all tissues examined. On the other hand, ALFIN-SLater et al. ${ }^{21)}$ state that the tocopherol content of the diet has little effect on the fatty acid composition of both triglyceride and phospholipid fractions of plasma and livers of rats.

The general pattern of changes in triglyceride distribution of the adult carp due to the tocopherol deficiency is essentially the same as that found in fingerlings and young carp, with the exception of the appearance of C-odd triglycerides in carp fingerlings. In all sizes of deficient fish examined the proportion of the C-54 triglyceride in the muscle was lowered by a lack of $\alpha$-tocopherol. Further study would be necessary to clarify unknown factors which are involved in the abnormal change of triglyceride pattern seen in the carp fingerlings.

The tocopherol deficiency in adult carp also revealed basically the same histological 
changes as those recognized in carp fingerlings. The depletion of tocopherol from the diet, especially in the case of adult carp, exerted significant effects on the pituitary-ovarian system and this clearly indicates that $\alpha$-tocopherol plays an important role in reproductive physiology in carp on the same basis as in higher animals. The significance of $\alpha$-tocopherol in the reproduction of fish must be analysed more precisely to establish actual dietary requirements.

\section{Acknowledgements}

We express here our sincere thanks to Drs. R. G. ACKMAN and P. H. Odense, Department of Environment, Fisheries and Marine Service, Canada who kindly read the manuscript and gave valuable suggestions.

\section{References}

1) T. Watanabe, F. Takashima, C. Ogino, and T. Hibiya: This Bull, 36, 623-630 (1970).

2) T. Watanabe, M. Matsu, T. Kawabata, and C. Ogino: ibid., 43, 813-817 (1977).

3) G. J. Nelson: Biochem. Biophys. Acta, 144, 221-232 (1967).

4) J. Folch, M. Lees, and G. H. S. Stanley: J. Biol. Chem., 226, 497-509 (1957).

5) M. Matsun, T. Watanabe, and N. IKeKaWA: This Bull., 39, 367-373 (1973).

6) T. Watanabe and T. TAKEUCHI: ibid., 42, 893-906 (1976).

7) T. Watanabe, F. Takashima, C. Ogino, and T. Hrbiya: ibid, 36, 972-976 (1970).

8) T. Watanabe, M. Matsur, F. Takashima, and N. IkeKaWa: ibid., 39, 375-382 (1973).

9) J. N. Ball and B. I. BaKer: In "Fish Physiology" (ed. by W. S. Hoar and D. J. Randall), Vol. II, Academic Press, New York, 1969, pp. 1-110.

10) M. M. O. BARRIE: Lancet, 233, 251-255 (1937).

11) S. C. LeE: Vitamins, 21, 528-537 (1960).

12) E. TonUtri: Z. Vitaminforsch., 13, 1-9 (1943).

13) K. E. Mason: Vitamins and Hormones, 2, 107-153 (1944).

14) W. L. Bryan and K. E. Mason: Am. J. Physiol., 131, 263-267 (1940/41).

15) H. Ko: Vitamins, 22, 207-214 (1961).

16) D. J. W. LeE and M. MCC. BarNes: Br. J. Nutr., 23, 289-295 (1969).

17) H. SuzuKI: Tohoku J. exp. Med, 106, 329-342 (1972).

18) T. Watanabe, I. Kobayashi, O. Otsue, and C. Ogino: This Bull., 40, 387-392 (1974).

19) J. D. Castell, R. O. Sinnhuber, D. J. Lee, and J. H. Wales: J. Nutrition, 102, 93-100 (1972).

20) T. Watanabe, T. TakeuchI, and C. Ogino: This Bull., 41, 263-269 (1975).

21) R. B. Alfin-Slater, Y. Shimma, H. Hansen, P. Wells, and L. Aftergood: J. Am. Oil Chem. Soc., 49, 395-402 (1972).

22) S.-N. LiN and E. C. Horning: J. Chromatography, 112, 483-497 (1975).

23) B. A. Underwood, C. R. Denning and M. Navab: Ann. N.Y. Acad. Sci., 203, 237 (1972). 


\section{Explanations of the Figures}

Fig. 1. Langerhans' islet of the control fish. AF positive cells (dark) are moderately granulated.

Fig. 2. Langerhans' islet of the $\alpha$-tocopherol deficient fish. Most of the AF positive cells are small and contained fewer granules.

Fig. 3. Hepatic cells of the control fish. Vacuoles within cytoplasm are thought to be glycogen in nature, confirmed by PAS-saliva test.

Fig. 4. Hepatic cells of the deficient fish. Cellular size is small and the amount of glycogen is less (HE).

Fig. 5. Mesoadenohypophysis of the control fish. The "g" cells in the Figure are AF positive and thought to be either the gonadotrophs or the thyrotrophs.

Fig. 6. Mesoadenohypophysis of the deficient fish. AF positive cells are small and contained fewer granules.

Fig. 7. Oocytes of the control fish. The "a" structure in the Figure is atretic oocytes (HE).

Fig. 8. Oocytes of the deficient fish. Advanced oocytes which have accumulated plentiful yolk-granules are seldomly observed. On the other hand, atretic oocytes (a) are numerous (HE).

Bar under the left in the Figures indicates respectively $10 \mathrm{~nm}$ in Figs. 1-6 and $100 \mathrm{~nm}$ in Figs. 7-8. 

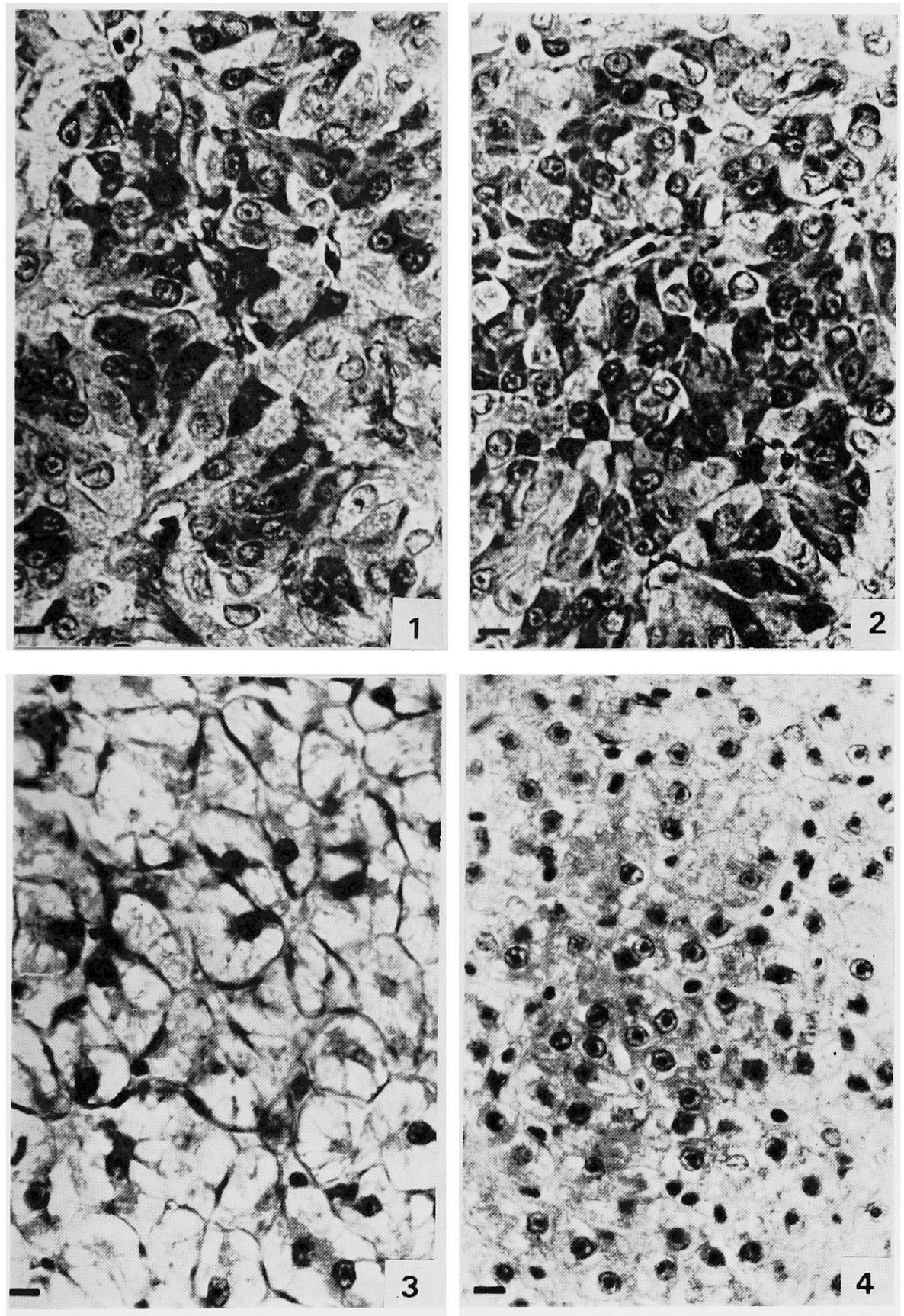

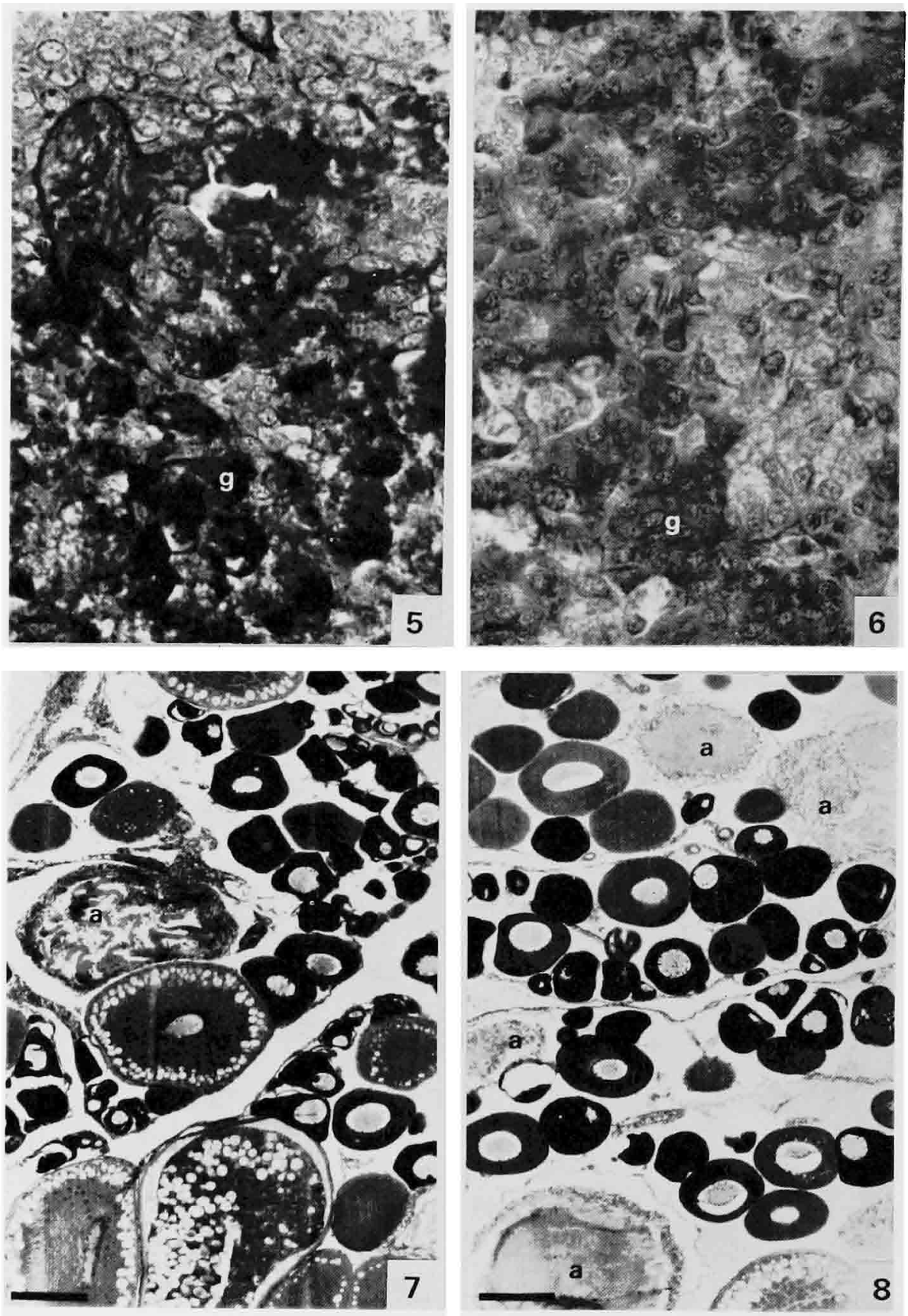